\title{
Effect of Lung Volume Reduction Surgery on Resting Pulmonary Hemodynamics in Severe Emphysema
}

\author{
Gerard J. Criner', Steven M. Scharf², Jeremy A. Falk1, John P. Gaughan', Alice L. Sternberg ${ }^{3}$, \\ Namrata B. Patel ${ }^{1}$, Henry E. Fessler ${ }^{3}$, Omar A. Minai ${ }^{4}$, and Alfred P. Fishman ${ }^{5}$, for the National Emphysema \\ Treatment Trial Research Group* \\ ${ }^{1}$ Temple University, Philadelphia, Pennsylvania; ${ }^{2}$ University of Maryland, Baltimore, Maryland; ${ }^{3}$ Johns Hopkins University, Baltimore, Maryland; \\ ${ }^{4}$ Cleveland Clinic Foundation, Cleveland, Ohio; and ${ }^{5}$ University of Pennsylvania, Philadelphia, Pennsylvania
}

\begin{abstract}
Rationale: To determine the effect of medical treatment versus lung volume reduction surgery (LVRS) on pulmonary hemodynamics. Methods: Three clinical centers of the National Emphysema Treatment Trial (NETT) screened patients for additional inclusion into a cardiovascular (CV) substudy. Demographics were determined, and lung function testing, six-minute-walk distance, and maximum cardiopulmonary exercise testing were done at baseline and 6 months after medical therapy or LVRS. CV substudy patients underwent right heart catheterization at rest prerandomization (baseline) and 6 months after treatment.

Measurements and Main Results: A total of 110 of the 163 patients evaluated for the CV substudy were randomized in NETT (53 were ineligible), 54 to medical treatment and 56 to LVRS. Fifty-five of these patients had both baseline and repeat right heart catheterization 6 months postrandomization. Baseline demographics and lung function data revealed CV substudy patients to be similar to the remaining 1,163 randomized NETT patients in terms of age, sex, $\mathrm{FEV}_{1}$, residual volume, diffusion capacity of carbon monoxide, $\mathrm{Pa}_{\mathrm{O}_{2}}$, $\mathrm{Pa}_{\mathrm{CO}_{2}}$, and six-minute-walk distance. $\mathrm{CV}$ substudy patients had moderate pulmonary hypertension at rest $(\overline{\mathrm{Ppa}}, 24.8 \pm 4.9 \mathrm{~mm} \mathrm{Hg})$; baseline hemodynamic measurements were similar across groups. Changes from baseline pressures to 6 months post-treatment were similar across treatment groups, except for a smaller change in pulmonary capillary wedge pressure at end-expiration post-LVRS compared with medical treatment ( -1.8 vs. $3.5 \mathrm{~mm} \mathrm{Hg}, \mathrm{p}=0.04)$. Conclusions: In comparison to medical therapy, LVRS was not associated with an increase in pulmonary artery pressures.
\end{abstract}

Keywords: emphysema; LVRS; lung volume reduction

Although the effects of emphysema on gas exchange and airflow obstruction have been well characterized, its effects on cardiovascular function are less well understood (1). Emphysema may adversely affect cardiovascular function by several different mechanisms. Hypoxemia, or destruction of lung tissue in associa-

(Received in original form August 8, 2006; accepted in final form May 10, 2007) The National Emphysema Treatment Trial is supported by the National Heart, Lung, and Blood Institute (contracts NO1HR76101, NO1HR76102, N01HR76103, N01HR76104, NO1HR76105, NO1HR76106, N01HR76107, NO1HR76108, NO1HR76109, NO1HR76110, NO1HR76111, NO1HR76112, NO1HR76113, NO1HR76114, NO1HR76115, NO1HR76116, NO1HR76118, and NO1HR76119), the Centers for Medicare and Medicaid Services, and the Agency for Healthcare Research and Quality.

* A complete list of NETT members may be found before the REFERENCES.

Correspondence and requests for reprints should be addressed to Gerard J. Criner, M.D., Pulmonary and Critical Care Medicine, Temple University School of Medicine, 3401 North Broad Street, Philadelphia, PA 19140. E-mail: crinerg@tuhs. temple.edu

This article has an online supplement, which is accessible from this issue's table of contents at www.atsjournals.org

Am J Respir Crit Care Med Vol 176. pp 253-260, 2007

Originally Published in Press as DOI: 10.1164/rccm.200608-1114OC on May 11, 2007

Internet address: www.atsjournals.org

\section{AT A GLANCE COMMENTARY}

Scientific Knowledge on the Subject

The effect of lung volume reduction surgery on pulmonary hemodynamics is controversial and has only been reported from small, uncontrolled, single-center trials.

\section{What This Study Adds to the Field}

In comparison to medical therapy, lung volume reduction surgery was not associated with an increase in pulmonary artery pressures.

tion with decreased cross-sectional area of the pulmonary vasculature, may increase pulmonary vascular resistance (PVR) (2-5). Hyperinflation may impair left (LV) or right ventricular (RV) diastolic filling (6-9). A sustained increase in RV afterload may eventually impair LV diastolic filling (diastolic interdependence) (10). Lung volume reduction surgery (LVRS) has the potential of either improving cardiovascular function by improving oxygenation and decreasing hyperinflation or worsening cardiovascular function by surgically removing or deforming the pulmonary vasculature.

Reports of the effects of LVRS on pulmonary hemodynamics and RV function have been inconsistent. Several authors have reported improvement in RV function after LVRS (11), a decrease in pulmonary capillary wedge pressure (PCWP) (12), decreased respiratory swings in pulmonary arterial diastolic pressure (13), and improvements in RV and LV diastolic filling and function $(14,15)$. Others have reported an increase in resting pulmonary arterial systolic pressures (16) and PVR (17), or no effect on the development of exercise-induced pulmonary hypertension (18) after LVRS. None of the above studies, however, examined the effects of LVRS in a prospective, randomized, and controlled trial.

The National Emphysema Treatment Trial (NETT), a large, prospective, randomized, multicenter, long-term trial that compared medical therapy with medical therapy plus LVRS provided an opportunity to assess the effects of LVRS on pulmonary arterial pressure and cardiac performance. We attempted to answer three questions: (1) What effect does LVRS have on resting pulmonary hemodynamics as compared with medical therapy, (2) What is the relationship between changes in lung function to changes in pulmonary hemodynamics after LVRS, and (3) What is the relationship between hemodynamic changes after LVRS and the changes that occur during exercise testing? 


\section{METHODS}

Three of the 17 NETT centers performed a cardiovascular substudy ( $\mathrm{CV}$ substudy), which was conducted in eligible patients after screening for the main NETT study. The design and methods of the main NETT have been previously described in detail (19). Of special significance for this substudy, patients were excluded from NETT if their mean pulmonary artery pressure ( $\overline{\mathrm{Ppa}})$ on right heart catheterization (RHC) was $35 \mathrm{~mm} \mathrm{Hg}$ or greater ( $38 \mathrm{~mm} \mathrm{Hg}$ in Denver, CO) or if their peak systolic pulmonary arterial (PAS) pressure on RHC was $45 \mathrm{~mm} \mathrm{Hg}$ or greater $(50 \mathrm{~mm} \mathrm{Hg}$ in Denver). RHC was undertaken to rule out pulmonary hypertension if PAS pressure on echocardiogram was $45 \mathrm{~mm} \mathrm{Hg}$ or greater.

\section{Clinical Assessment}

Demographic data and medical histories were collected using standardized instruments (19). Pulmonary function testing as defined in NETT was performed using American Thoracic Society guidelines (20-23). Exercise capacity was measured by the standardized six-minute-walk distance (6MWD) test and by standard maximum symptom-limited cycle ergometry using graded exercise loading per NETT guidelines.

\section{Computed Tomography Scanning}

Radiologists classified the craniocaudal distribution of emphysema as predominantly affecting the upper lobes (upper lobe predominant), or as predominately involving either, the superior segment of either of the lower lobes, or the lower lobes diffusely. These latter classifications were grouped together and denoted as having a non-upper lobe predominant radiographic pattern of emphysema (24).

\section{RHC}

RHC was performed by experienced cardiologists while the patients were supine at rest before rehabilitation (baseline) and 6 months postrandomization to treatment. Supplemental oxygen was given as needed to maintain an arterial oxygen saturation of $90 \%$ or greater. Measurements included right atrial (RA), RV, pulmonary arterial (PA), pulmonary capillary wedge $(\mathrm{PCW})$, and systemic arterial pressures, as well as arterial and mixed venous $\mathrm{O}_{2}$ saturations $\left(\mathrm{Sa}_{\mathrm{O}_{2}}\right.$ and $\mathrm{S}_{\mathrm{O}_{2}}$, respectively), and cardiac output (CO) by thermodilution. All pressures were measured at end-inspiration and end-expiration, and labeled with subscript insp and exp, respectively. $* \overline{\mathrm{Ppa}}$ was calculated as follows: $\overline{\mathrm{Ppa}}=\mathrm{PA}_{\text {diastolic }}+$ one-third of the pulse pressure at end-inspiration and end-expiration. PVR was calculated as PVR $=[(\overline{\mathrm{Ppa}}-\mathrm{PCWP}) / \mathrm{CO}] \times 79.9\left(\right.$ dyne $\left.\cdot \mathrm{s} \cdot \mathrm{cm}^{-5}\right)$. Systemic vascular resistance $(\mathrm{SVR})$ was calculated as SVR $=[(\overline{\mathrm{Ppa}}-$ $\mathrm{RAP}) / \mathrm{CO}] \times 79.9\left(\right.$ dyne $\left.\cdot \mathrm{s} \cdot \mathrm{cm}^{-5}\right)$. Stroke volume $(\mathrm{SV})$ was calculated as $\mathrm{SV}=\mathrm{CO} / \mathrm{HR}$.

Within a few days of RHC, both at baseline and 6 months after randomization to treatment, patients underwent multigated pooled radionuclide angiography (MUGA) while supine at rest for measurement of LV and RV ejection fractions (LVEF and RVEF, respectively). LVEF and RVEF were calculated as ejection fraction $(E F)=$ (enddiastolic - end-systolic counts)/end-diastolic counts.

We assumed that the $\mathrm{CO}$ measured at rest during RHC and during the gated pooled scan was equal for the calculations of SVs, and LV and RV end-diastolic and end-systolic volumes. Incorporating measurements from RHC and MUGA, the RV and LV end-diastolic volumes (EDVs) and end-systolic volumes (ESVs) were calculated as EDV = $\mathrm{SV} / \mathrm{EF}$ and $\mathrm{ESV}=\mathrm{EDV}-\mathrm{SV}$, respectively.

\section{Statistics}

All data are expressed as the mean \pm SD. The differences between the continuous variables in the two treatment groups and between the study groups were analyzed using analysis of variance (ANOVA). Binary categorical variables were analyzed using the Fisher exact test. Differences between demographic data in patients who had hemodynamic data both at baseline and 6 months postrandomization were analyzed using unpaired $t$ tests. Treatment effect was measured using ANOVA followed by pairwise group comparisons with Bonferroni adjustments. Correlations were done using Pearson correlation coefficients.

\section{RESULTS}

Figure 1 shows the total number of NETT and CV substudy patients screened for inclusion in the trial, the number randomized to treatment, and those CV substudy patients who had baseline and repeat RHC 6 months postrandomization for treatment. A total of 3,777 patients were screened for NETT; this number included 163 patients screened for the CV substudy. A total of 2,559 screened patients were deemed ineligible by NETT testing, including 53 patients for the CV substudy; 55 of the 110 (27 medical, 28 LVRS) randomized patients in the CV substudy underwent repeat RHC 6 months postrandomization to treatment and form the study group (Figure 1).

Table 1 shows reasons for patient ineligibility in the NETT main study, or the failure to repeat RHC after randomization to treatment in the $\mathrm{CV}$ substudy. The most common reasons why patients were ineligible for the NETT included failure to meet pulmonary function or computed tomography scan criteria, cardiac abnormalities, or the patient was deemed unfit for LVRS by physician evaluation. The most frequent reason why NETT main study patients did not participate in the CV substudy was refusal to undergo RHC. Of the 53 patients who failed to repeat RHC at 6 months, the most common reasons for failure included the following: illness, refusal to repeat RHC, or inability to travel back to the NETT center for repeat testing. Individual patients may have had more than one reason for ineligibility, either for the NETT main study, or for failure to repeat RHC. The reasons why patients enrolled in the CV substudy did not undergo repeat RHC were equally distributed between the LVRS and medical groups.

Table 2 shows baseline demographics of the 1,163 randomized patients who were not a part of the CV substudy or who did not undergo repeat RHC 6 months after randomization (non$\mathrm{CV}$ ) versus the 55 randomized patients who were enrolled into the CV substudy and had repeat RHC 6 months postrandomization to treatment. Both groups of patients were comparable in terms of age, sex, severity of airflow obstruction, degree of gas trapping, diffusing capacity, and extent of gas exchange impairment. Although it was statistically significant that patients in the CV substudy were slightly less hyperinflated compared with the non-CV group at baseline (TLC: $128.5+15.2$ vs. $122.2+11.9 \%$ predicted, $\mathrm{p}=0.0003)$, the small magnitude of difference was

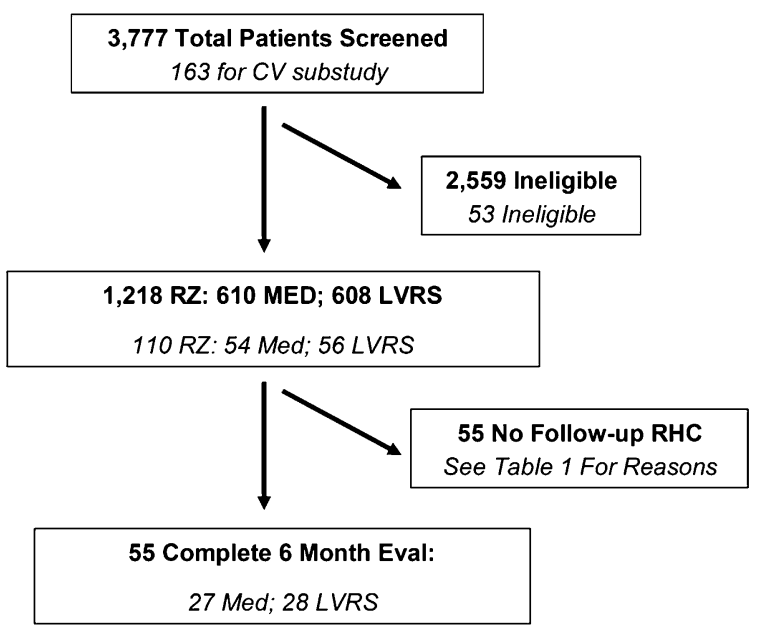

Figure 1. Overview of National Emphysema Treatment Trial (NETT) and cardiovascular (CV) substudy patient enrollment. All NETT patients, including the CV substudy patients, are in bold and not italicized; CV substudy patients are shown in italics. Eval, evaluation; LVRS, lung volume reduction surgery; RZ, randomized. 
TABLE 1. REASONS FOR NATIONAL EMPHYSEMA TREATMENT TRIAL MAIN STUDY INELIGIBILITY OR FAILURE TO REPEAT CARDIOVASCULAR SUBSTUDY RIGHT HEART CATHETERIZATION POST-TREATMENT

\begin{tabular}{ll}
\hline No. of Ineligible Patients $\left(n=53^{*}\right)$ & No. of Patients with No Repeat RHC $\left(n=53^{*}\right)$ \\
\hline $\begin{array}{l}\text { PFT/CT criteria not met, 19 } \\
\text { Cardiac abnormalities, 15 }\end{array}$ & Died, 7 \\
Refused testing, 6 & Missed repeat RHC, 46 (5 missed entire visit, 41 completed part of the visit) \\
Failed physician evaluation, 11 & Refused, 37 \\
Pulmonary nodules, 2 & Uness, 9 \\
Failed BMl criteria, 2 & Test ordered, but not done, 2 \\
Too high prednisone dose, 2 & Too tired, 1 \\
Died before randomization, 2 & Away from area, 1 \\
Current disease, 3 & Waveform unreadable, 1 \\
Other, 6 & No information, 3 \\
\hline
\end{tabular}

Definition of abbreviations: $\mathrm{BMI}=$ body mass index; $\mathrm{CT}=$ chest computed tomography; $\mathrm{PFT}=$ pulmonary function testing; $\mathrm{RHC}=$ right heart catheterization.

* Patients could have had more than one reason for ineligibility or failure to repeat RHC.

Two patients were missing baseline RHC data so that change from baseline to 6 months could not be calculated.

unlikely to be clinically meaningful. Patients in the CV substudy were similar to the remainder of the NETT group in terms of the percentage who had low exercise profile on baseline cardiopulmonary exercise testing, upper lobe-predominant disease by computed tomography scan, baseline performance on the 6MWD test, and body mass index. Patients who were enrolled in the substudy, however, achieved a greater maximum wattage on baseline cardiopulmonary exercise testing (46.1 \pm 25.3 vs. $38.7 \pm 21.4 \mathrm{~W}, \mathrm{p}=0.01)$ than did the remainder of patients enrolled into NETT.

Table 3 shows baseline hemodynamic variables in CV substudy patients with follow-up data who were randomized to either the medical or LVRS groups. Both patient groups had moderate resting pulmonary hypertension and normal LV function. There was no significant difference in any baseline cardiovascular parameter between the groups.

Table 4 shows values at baseline and 6 months after randomization to treatment. The data include pulmonary function studies, gas exchange, 6MWD tests, and performance on maximum symptom-limited cardiopulmonary exercise tests. Patients in the CV substudy who received LVRS had significantly greater

TABLE 2. BASELINE DEMOGRAPHICS

\begin{tabular}{lccc}
\hline & $\begin{array}{c}\text { Non-CV } \\
(n=1163)\end{array}$ & $\begin{array}{c}\mathrm{CV} \\
(n=55)\end{array}$ & $\mathrm{p}$ Value \\
\hline Age, yr & $66.5 \pm 6.1$ & $64.9 \pm 7.0$ & 0.061 \\
$\mathrm{Sex}, \%$ female & 38.7 & 40 & 0.89 \\
$\mathrm{FEV}_{1}, \%$ & $26.7 \pm 7.2$ & $26.9 \pm 6.8$ & 0.87 \\
$\mathrm{TLC}, \%$ & $128.5 \pm 15.2$ & $122.2 \pm 11.9$ & 0.0003 \\
$\mathrm{RV}, \%$ & $222.3 \pm 49.6$ & $212.8 \pm 44.9$ & 0.16 \\
$\mathrm{DL}_{\mathrm{CO}}, \%$ & $28.3 \pm 9.7$ & $29.0 \pm 9.8$ & 0.59 \\
$\mathrm{~Pa}_{\mathrm{O}^{\prime}}$ mm Hg & $64.3 \pm 10.3$ & $64.9 \pm 10.8$ & 0.67 \\
$\mathrm{~Pa}_{\mathrm{CO}}, \mathrm{mm} \mathrm{Hg}$ & $43.1 \pm 5.8$ & $44.3 \pm 5.6$ & 0.14 \\
$\mathrm{LoW}_{\mathrm{EX}} \%$ & 45.4 & 36.4 & 0.21 \\
$\mathrm{UL} \mathrm{predominant,} \mathrm{\%}$ & 65.3 & 57.4 & 0.25 \\
$6 \mathrm{MWD}^{\prime} \mathrm{ft}$ & $1,216 \pm 314$ & $1,245 \pm 324$ & 0.51 \\
Max watts & $38.7 \pm 21.4$ & $46.1 \pm 25.3$ & 0.01 \\
$\mathrm{BMI}$ & $24.8 \pm 3.9$ & $24.5 \pm 4.0$ & 0.64 \\
\hline
\end{tabular}

Definition of abbreviations: $\mathrm{CV}=$ cardiovascular (substudy); $\mathrm{D}_{\mathrm{CO}}=$ diffusing capacity of carbon monoxide; LoW $_{\mathrm{EX}}=$ low exercise performance on cardiopulmonary exercise test ( $\leqslant 40 \mathrm{~W}$ if male, $\leqslant 25 \mathrm{~W}$ if female); Max watts = maximum wattage attained on cardiopulmonary exercise testing; Non-CV = NETT patients not enrolled in CV substudy or not completing the 6-month CV substudy evaluation; RV = residual volume; $6 \mathrm{MWD}=$ six-minute-walk distance; UL predominant; upper lobe predominant disease on computed tomography scan.
$\mathrm{FEV}_{1 \%}$ predicted, smaller lung volumes, greater diffusion capacity, higher $\mathrm{Pa}_{\mathrm{O}_{2}}$, and lower $\mathrm{Pa}_{\mathrm{CO}_{2}}$ than did medical patients 6 months after randomization. At 6 months, the 6MWD and maximum wattage accomplished during exercise were similar.

Figure 2 displays changes in end-expiratory RHC pressures from baseline to 6 months postrandomization to treatment. There was no significant change in RHC pressures 6 months after randomization to treatment in the medical group compared with baseline. The changes in expiratory pressures post-LVRS tended to be slightly lower compared with the changes observed

TABLE 3. BASELINE HEMODYNAMIC VARIABLES IN MEDICAL AND LUNG VOLUME REDUCTION SURGERY GROUPS

\begin{tabular}{|c|c|c|c|c|c|}
\hline & Medical $(n=27)$ & $\mathrm{n}$ & $\operatorname{LVRS}(n=28)$ & $\mathrm{n}$ & $p$ Value \\
\hline MAP, mm Hg & $97.6 \pm 12.0$ & 25 & $100.5 \pm 14.5$ & 27 & 0.45 \\
\hline $\mathrm{RA}_{\text {exp }}, \mathrm{mm} \mathrm{Hg}$ & $10.5 \pm 8.7$ & 27 & $8.2 \pm 2.9$ & 28 & 0.20 \\
\hline $\mathrm{RVS}_{\text {exp }}, \mathrm{mm} \mathrm{Hg}$ & $36.4 \pm 6.6$ & 27 & $37.4 \pm 7.9$ & 28 & 0.64 \\
\hline $\mathrm{RVD}_{\text {exp }}, \mathrm{mm} \mathrm{Hg}$ & $8.7 \pm 5.2$ & 26 & $8.1 \pm 5.1$ & 28 & 0.64 \\
\hline $\mathrm{PAS}_{\text {exp, }} \mathrm{mm} \mathrm{Hg}$ & $36.6 \pm 5.7$ & 27 & $36.4 \pm 6.8$ & 27 & 0.91 \\
\hline $\mathrm{PAD}_{\text {exp }}, \mathrm{mm} \mathrm{Hg}$ & $18.6 \pm 4.3$ & 27 & $19.3 \pm 5.2$ & 27 & 0.62 \\
\hline$\overline{\mathrm{Ppa}}_{\text {exp }}, \mathrm{mm} \mathrm{Hg}$ & $24.6 \pm 4.4$ & 27 & $25.0 \pm 5.4$ & 27 & 0.78 \\
\hline $\mathrm{PCWP}_{\exp }, \mathrm{mm} \mathrm{Hg}$ & $13.2 \pm 4.1$ & 27 & $14.2 \pm 5.7$ & 28 & 0.45 \\
\hline $\mathrm{CO}, \mathrm{L} / \mathrm{min}$ & $5.1 \pm 0.9$ & 27 & $5.6 \pm 1.7$ & 27 & 0.21 \\
\hline $\mathrm{HR}$, beats/min & $77.9 \pm 12.3$ & 26 & $84.1 \pm 11.9$ & 26 & 0.07 \\
\hline$S \bar{v}_{\mathrm{O}_{2}}, \%$ & $71 \pm 4$ & 24 & $71 \pm 7$ & 27 & 0.65 \\
\hline $\mathrm{Sa}_{\mathrm{O}_{2}}, \%$ & $97 \pm 2$ & 25 & $97 \pm 3$ & 27 & 0.75 \\
\hline RVEF, \% & $38 \pm 5$ & 10 & $38 \pm 5$ & 14 & 0.68 \\
\hline LVEF, \% & $58 \pm 10$ & 19 & $61 \pm 8$ & 15 & 0.38 \\
\hline $\mathrm{Cl}, \mathrm{L} / \mathrm{min} / \mathrm{m}^{2}$ & $2.9 \pm 0.5$ & 27 & $3.2 \pm 0.9$ & 27 & 0.14 \\
\hline SVR, dyne $\cdot \mathrm{s} \cdot \mathrm{cm}^{-5}$ & $1,448.2 \pm 486.6$ & 25 & $1,424.8 \pm 490.8$ & 26 & 0.87 \\
\hline PVR, dyne $\cdot \mathrm{s} \cdot \mathrm{cm}^{-5}$ & $185.8 \pm 77.4$ & 27 & $164.5 \pm 98.3$ & 27 & 0.38 \\
\hline $\mathrm{SV}, \mathrm{ml}$ & $66.0 \pm 14.2$ & 26 & $66.4 \pm 17.9$ & 26 & 0.93 \\
\hline LVEDV, ml & $110.8 \pm 21.2$ & 18 & $111.6 \pm 28.3$ & 14 & 0.92 \\
\hline RVEDV, ml & $186.9 \pm 45.4$ & 10 & $191.4 \pm 43.4$ & 13 & 0.81 \\
\hline LVESV, ml & $46.7 \pm 15.9$ & 18 & $45.3 \pm 19.2$ & 14 & 0.82 \\
\hline RVESV, ml & $115.5 \pm 31.1$ & 10 & $120.3 \pm 30.4$ & 13 & 0.72 \\
\hline
\end{tabular}

Definition of abbreviations: $\mathrm{Cl}=$ cardiac index; $\mathrm{CO}=$ cardiac output; $\mathrm{LVEF}=$ left ventricular ejection fraction; LVEDV = left ventricular end-diastolic volume; LVESV = left ventricular end-systolic volume; LVRS = lung volume reduction surgery; $\mathrm{MAP}=$ mean systemic arterial pressure; $\mathrm{PAD}=$ pulmonary artery diastolic; $\mathrm{PAS}=$ pulmonary artery systolic; PCWP = pulmonary capillary wedge pressure; $\overline{\mathrm{Ppa}}=$ pulmonary artery mean; $\mathrm{PVR}=$ pulmonary vascular resistance; $\mathrm{RA}=$ right atrial; RVD = right ventricular diastolic; RVEDV = right ventricular end-diastolic volume; RVEF = right ventricular ejection fraction; RVESV = right ventricular endsystolic volume; RVS = right ventricular systolic; $\mathrm{Sa}_{\mathrm{O}_{2}}=$ arterial saturation; $S \overline{\mathrm{O}}_{\mathrm{O}_{2}}=$ mixed venous $\mathrm{O}_{2}$ saturation; $\mathrm{SV}=$ stroke volume; $\mathrm{SVR}=$ systemic vascular resistance. 
TABLE 4. PULMONARY FUNCTION TESTING AND EXERCISE DATA AT BASELINE AND 6 MONTHS POSTRANDOMIZATION TO TREATMENT

\begin{tabular}{|c|c|c|c|c|c|c|}
\hline & \multicolumn{3}{|c|}{ Baseline } & \multicolumn{3}{|c|}{$6 \mathrm{mo}$} \\
\hline & $\operatorname{Med}(n=27)$ & $\operatorname{LVRS}(n=28)$ & $\mathrm{p}$ & $\operatorname{Med}(n=27)$ & $\operatorname{LVRS}(n=28)$ & $\mathrm{p}$ \\
\hline $\mathrm{FEV}_{1}, \%$ & $28.2 \pm 6.6$ & $25.7 \pm 6.9$ & 0.18 & $26.4 \pm 6.5$ & $34.3 \pm 9.9^{*}$ & 0.001 \\
\hline TLC, \% & $121.4 \pm 8.1$ & $123.0 \pm 14.8$ & 0.63 & $123.8 \pm 10.5$ & $107.7 \pm 15.0^{*}$ & $<0.001$ \\
\hline $\mathrm{RV}, \%$ & $203.1 \pm 28.6$ & $222.2 \pm 55.3$ & 0.11 & $216.2 \pm 39.7$ & $165.1 \pm 38.6^{*}$ & $<0.001$ \\
\hline $\mathrm{DL}_{\mathrm{CO}}, \%$ & $\begin{array}{c}30.1 \pm 8.1 \\
(n=27)\end{array}$ & $\begin{array}{c}28.0 \pm 11.3 \\
(n=28)\end{array}$ & 0.44 & $\begin{array}{c}29.7 \pm 8.9 \\
(n=22)^{\dagger}\end{array}$ & $\begin{array}{l}31.2 \pm 12.0 \\
(\mathrm{n}=25)^{\dagger}\end{array}$ & 0.65 \\
\hline $\mathrm{Pa}_{\mathrm{O}_{2}}, \mathrm{~mm} \mathrm{Hg}$ & $64.4 \pm 8.7$ & $65.5 \pm 12.6$ & 0.70 & $64.11 \pm 9.7$ & $73.8 \pm 11.7^{*}$ & 0.002 \\
\hline $\mathrm{Pa}_{\mathrm{CO}_{2}}, \mathrm{~mm} \mathrm{Hg}$ & $44.6 \pm 5.0$ & $43.9 \pm 6.3$ & 0.65 & $46.0 \pm 5.8$ & $40.3 \pm 4.6^{*}$ & $<0.001$ \\
\hline $6 \mathrm{MWD}, \mathrm{ft}$ & $\begin{array}{c}1,252 \pm 352 \\
(n=27)\end{array}$ & $1,238 \pm 300$ & 0.87 & $\begin{array}{c}1,203 \pm 358 \\
(n=25)\end{array}$ & $1,313 \pm 313$ & 0.24 \\
\hline Max watts & $\begin{array}{c}49.4 \pm 23.9 \\
(n=27)\end{array}$ & $\begin{array}{l}42.8 \pm 26.6 \\
(n=28)\end{array}$ & 0.33 & $\begin{array}{c}44.5 \pm 27.9 \\
(n=26)\end{array}$ & $\begin{array}{l}49.9 \pm 22.5 \\
(n=26)\end{array}$ & 0.45 \\
\hline
\end{tabular}

Definition of abbreviations: $\mathrm{DI}_{\mathrm{CO}}=$ diffusing capacity of carbon monoxide; Max watts = maximum wattage on cardiopulmonary exercise testing; Med = medical (treatment group); $6 \mathrm{MWD}=$ six-minute-walk distance; $\mathrm{RV}=$ residual volume.

${ }^{*} \mathrm{p}<0.05$ compared with baseline measurement.

$\dagger$ Performed at $12 \mathrm{mo}$.

in patients continuing with medical therapy. None of the changes were statistically significant.

Figure 3 shows, however, that change in resting endexpiratory PCWP $\left(\mathrm{PCWP}_{\exp }\right) 6$ months after randomization to treatment was significantly lower in patients who underwent LVRS compared with those receiving medical treatment.

Figure 4 shows respiratory swings (end-expiratory - endinspiratory) in pulmonary artery pressures at baseline and 6 months after treatment. There were no differences in the respiratory swings in pulmonary artery pressure between the two groups at baseline or after treatment.

Table 5 compares changes in other hemodynamic values from baseline to 6 months after randomization to treatment. Changes in $\overline{\mathrm{Ppa}}, \mathrm{CO}, \mathrm{S}_{\mathrm{O}_{2}}, \mathrm{Sa}_{\mathrm{O}_{2}}$, and $\mathrm{RVEF}$, measured by gated pooled analysis, were similar in the two groups.

No correlation was found between changes in $\mathrm{FEV}_{1}$ postLVRS and changes in LV end-diastolic volume index, and LV end-systolic volume index. Increases in $\mathrm{Pa}_{\mathrm{O}_{2}}$ correlated with improvement in $\operatorname{RVEF}(r=0.776, \mathrm{p}=0.024, \mathrm{n}=8)$ and inversely with a reduction in $\operatorname{PCWP}_{\text {exp }}(r=-0.379, \mathrm{p}=0.05, \mathrm{n}=28)$.
Changes in expiratory $\overline{\mathrm{Ppa}}\left(\overline{\mathrm{Ppa}}_{\mathrm{exp}}, r=-0.517, \mathrm{p}=0.006, \mathrm{n}=\right.$ 27) and $\mathrm{PCWP}_{\text {exp }}(r=-0.328, \mathrm{p}=0.089, \mathrm{n}=28)$ inversely correlated with the change in $\mathrm{FEV}_{1}$. Inverse correlations between 6MWD and LV end-diastolic volume index $(r=-0.642, \mathrm{p}=$ $0.033, \mathrm{n}=11)$ and LV end-systolic volume index $(r=-0.627$, $\mathrm{p}=0.039, \mathrm{n}=11)$, as well as between $\overline{\mathrm{Ppa}}_{\text {exp }}(r=-0.536, \mathrm{p}=$ $0.005, \mathrm{n}=26)$ and $\mathrm{PCWP}_{\exp }(r=-0.432, \mathrm{p}=0.027, \mathrm{n}=26)$, with maximum work performed on cardiopulmonary exercise testing, were found.

\section{DISCUSSION}

In comparison to optimal medical treatment, LVRS minimally reduces resting end-expiratory PCWP in severe emphysema. However, it evinces no other significant effects on measured and calculated cardiac performance variables at rest. We found that, after LVRS, changes in $\mathrm{FEV}_{1}$ correlated inversely with changes in $\overline{\mathrm{Ppa}}$ and changes in $\mathrm{Pa}_{\mathrm{O}_{2}}$ correlated directly with changes in RVEF. Changes in 6MWD and maximum work during cardiopulmonary exercise test correlated with changes in LV volume

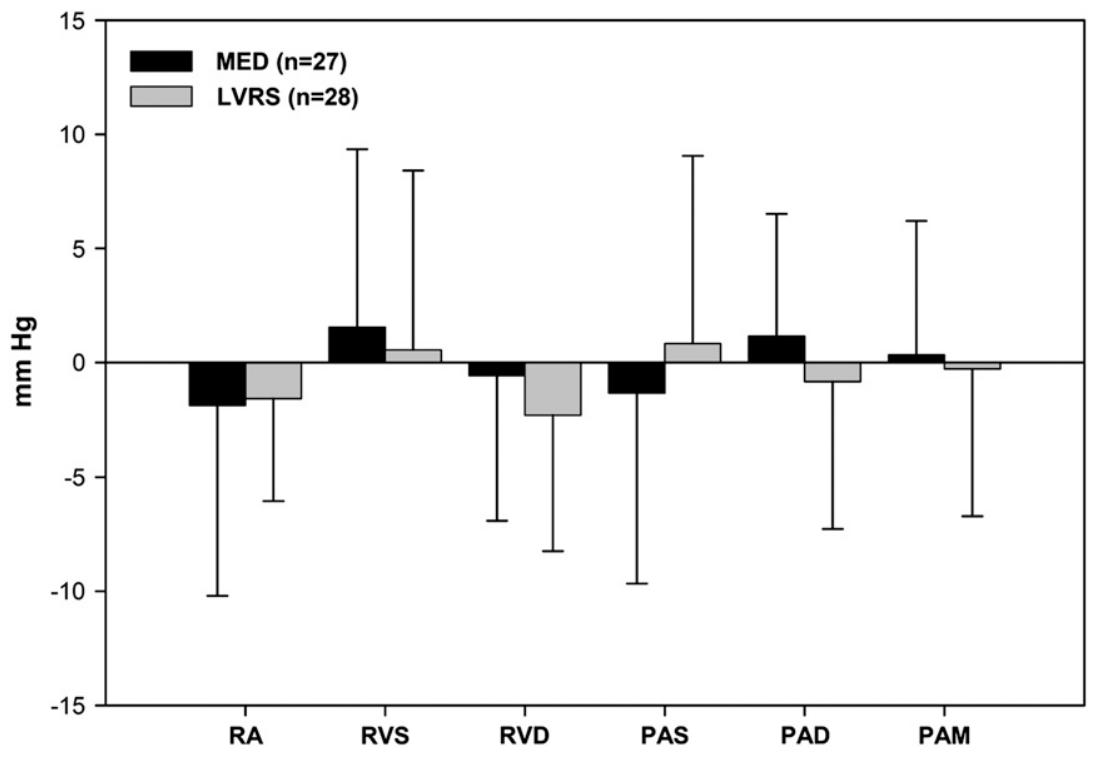

Figure 2. Changes in end-expiratory right heart catheterization pressures from baseline to 6 months after randomization to treatment compared with baseline. End-expiratory pressures post-lung volume reduction surgery (LVRS) tended to be slightly lower compared with patients who were medically treated (MED), but none of the differences achieved statistical significance. PAD, pulmonary artery diastolic; PAM, pulmonary artery mean; RA, right atrial; RVD, right ventricular diastolic; RVS, right ventricular systolic; PAS, pulmonary artery systolic. 


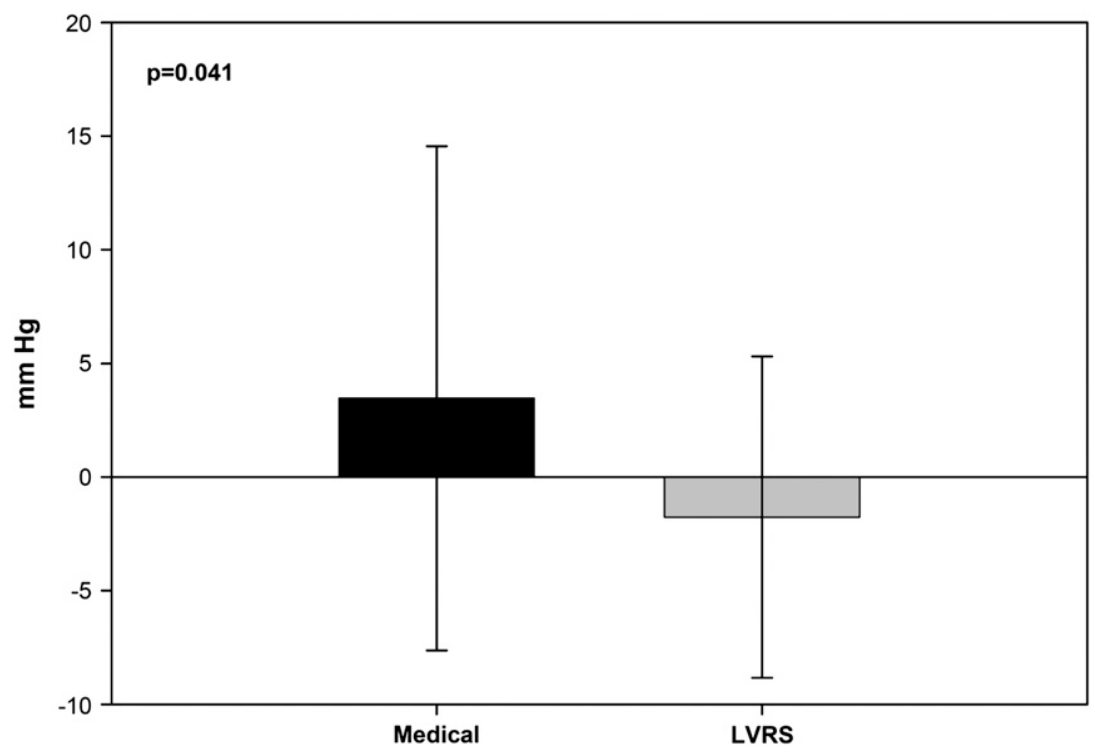

Figure 3. Change in end-expiratory pulmonary capillary wedge pressure $\left(\right.$ PCWP $\left._{\exp }\right)$ from baseline to 6 months after randomization to treatment. The reduction in PCWP exp seen after lung volume reduction surgery (LVRS) $(-1.76 \pm 7.1 \mathrm{~mm} \mathrm{Hg})$ was significantly different from the increases in PCWP $P_{\exp }$ observed in the medical treatment group $(3.46+11.1 \mathrm{~mm} \mathrm{Hg}, \mathrm{p}=0.04)$.

indices and a reduction in pulmonary arterial pressures at endexpiration, respectively. These data suggest that LVRS does not induce significant pulmonary hypertension.

A major concern has been that resection of 20 to $30 \%$ of each lung during LVRS impairs an already compromised pulmonary vascular bed, and leads to postoperative pulmonary hypertension (25). The development of secondary pulmonary hypertension in chronic obstructive pulmonary disease (e.g., emphysema) is ominous and denotes patients at greater risk for hospitalization (26), reduced exercise tolerance (27), and higher mortality (28, 29). Several authors have reported that LVRS worsens pulmonary hemodynamics $(16,17)$. Similarly, in emphysematous animal models, LVRS produced increases in pulmonary arterial pressure that varied with the extent of resection $(30,31)$.

Other investigators have not found LVRS to increase pulmonary arterial pressures. Kubo and colleagues (12) reported no increase in pulmonary arterial pressures at rest, or during exercise 6 months after bilateral LVRS. Oswald-Mammosser and coworkers (13) reported no increase in $\overline{\mathrm{Ppa}}$ at rest or during exercise 3 to 12 months after bilateral LVRS. Similar results were reported by Haniuda and colleagues (18), who found no increase in pulmonary arterial pressures at rest or during exercise in patients undergoing repeat RHC 6 months after bilateral LVRS.

Our data reaffirm that pulmonary arterial hypertension is not a significant complication of LVRS. We report these findings in a patient group with moderate pulmonary hypertension at baseline, a pulmonary hemodynamic profile that represents the majority of patients presenting for LVRS evaluation. Our baseline $\overline{\mathrm{Ppa}}$ was $24.62 \pm 4.35 \mathrm{~mm} \mathrm{Hg}$, which was the magnitude of secondary pulmonary hypertension ( $\overline{\mathrm{Ppa}}$ range: $>20 \leqslant 35 \mathrm{~mm}$ $\mathrm{Hg}$ ) that was found in $85.8 \%$ of patients evaluated who presented for entry into NETT (32). Our findings are clinically relevant in that we describe the effects of LVRS on the pulmonary vascular bed in the category of patients most likely to undergo LVRS.

The reduction in $\mathrm{PCWP}_{\mathrm{EXP}}$ that we found is similar to the reduction in $\mathrm{PCWP}_{\mathrm{EXP}}$ and to the swings in pulmonary arterial pressure reported at rest and during exercise after LVRS reported by others (17). A higher PCWP has been previously reported in patients with moderate to severe chronic obstructive

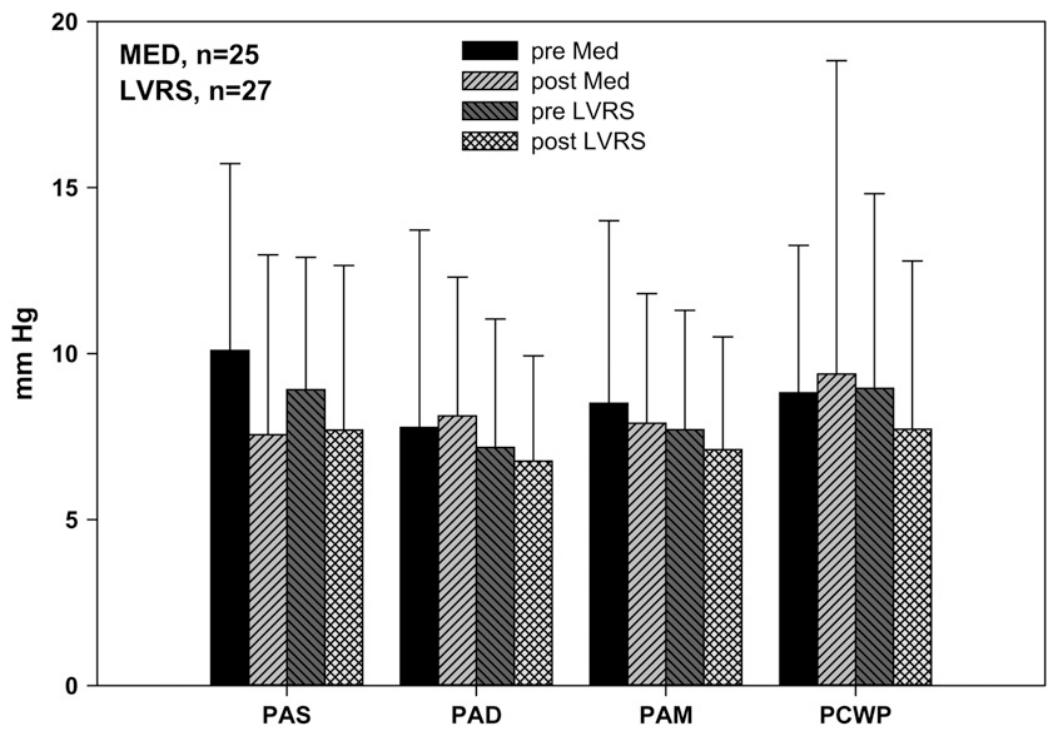

Figure 4. Respiratory swings of pulmonary artery pressures before and after treatment. There was no significant effect of lung volume reduction surgery (LVRS) on the respiratory swings in pulmonary artery pressures at rest compared with medical therapy (MED/Med). PAD, pulmonary artery diastolic pressure; PAM, pulmonary artery mean pressure; PAS, pulmonary artery systolic pressure; PCWP, pulmonary capillary wedge pressure. 
TABLE 5. CHANGES IN OTHER HEMODYNAMIC VALUES FROM BASELINE TO 6 MONTHS AFTER RANDOMIZATION TO TREATMENT

\begin{tabular}{lcccrc}
\hline & Med & $\mathrm{n}$ & LVRS & $\mathrm{n}$ & $\mathrm{p}$ Value \\
\hline$\overline{\mathrm{Ppa}}, \mathrm{mm} \mathrm{Hg}$ & $2.8 \pm 13.3$ & 21 & $2.1 \pm 15.5$ & 21 & 0.89 \\
$\mathrm{CO}, \mathrm{L} / \mathrm{min}$ & $-0.3 \pm 1.4$ & 26 & $-0.7 \pm 1.9$ & 26 & 0.36 \\
$\mathrm{HR}, \mathrm{beat} / \mathrm{min}$ & $0.46 \pm 8.01$ & 26 & $-3.69 \pm 12.69$ & 26 & 0.16 \\
$\mathrm{~S}_{\mathrm{O}_{2^{\prime}}} \%$ & $-0.6 \pm 4.2$ & 23 & $-1.0 \pm 7.4$ & 23 & 0.83 \\
$\mathrm{Sa}_{\mathrm{O}_{2}} \%$ & $-0.4 \pm 2.5$ & 25 & $0.0 \pm 3.1$ & 25 & 0.58 \\
$\mathrm{RVEF}, \%$ & $1.4 \pm 15.7$ & 5 & $-1.8 \pm 8.5$ & 8 & 0.64 \\
$\mathrm{LVEF}, \%$ & $4.4 \pm 8.5$ & 17 & $-0.7 \pm 5.8$ & 12 & 0.08
\end{tabular}

Definition of abbreviations: $\mathrm{CO}=$ cardiac output; HR = heart rate; LVEF = left ventricular ejection fraction; LVRS = lung volume reduction surgery; Med = medical (treatment group); $\overline{\mathrm{Ppa}}=$ mean arterial pressure; $\mathrm{RVEF}=$ right ventricular ejection fraction; $\mathrm{Sa}_{\mathrm{O}_{2}}=$ arterial oxygen saturation; $\mathrm{S}_{\mathrm{O}_{2}}=$ mixed venous $\mathrm{O}_{2}$ saturation.

pulmonary disease, and occurs without LV dysfunction. Our data showing a reduction in $\mathrm{PCWP}_{\exp }$ after LVRS without a change in $\mathrm{RV}$ or $\mathrm{LV}$ function suggest that $\mathrm{PCWP}_{\exp }$ reflects higher intrathoracic pressures in our severely obstructed, hyperinflated patient group, rather than any LV dysfunction. It also reaffirms the findings of others (33-35) that the hyperinflation associated with emphysema contributes to the elevation in PCWP $_{\text {exp. }}$.

The lack of correlation of consistent changes in pulmonary hemodynamics and exercise performance is not unexpected. The majority of patients with severe emphysema experience respiratory- not cardiac-related limitations while exercising. This is particularly notable in our patient group, for which cardiac dysfunction was screened out using sophisticated testing as per the NETT protocol. Therefore, our patient group is even more likely to represent a cohort in whom respiratory rather than cardiac limitation was the most important impediment to exercise.

We found an inverse correlation post-LVRS between changes in $\mathrm{FEV}_{1}$ and changes in $\overline{\mathrm{Ppa}}_{\text {exp }}$, consistent with the findings of others. We also found a correlation between an improvement in $\mathrm{RV}$ function and oxygenation in patients who underwent LVRS. An improvement in $\mathrm{Pa}_{\mathrm{O}_{2}}$ correlated inversely with a reduction in $\mathrm{PCWP}_{\text {exp. }}$. An improvement in oxygenation has been repeatedly found by others to result in a reduction in pulmonary artery pressures (26), PVR (5), and an improvement in RV function (27).

We noted inverse correlations between 6MWD and LV enddiastolic volume index and LV end-systolic volume index, as well as $\overline{\mathrm{Ppa}}_{\mathrm{exp}}$ and $\mathrm{PCWP}_{\exp }$ with maximum work performed on cardiopulmonary exercise testing. In contrast to the findings of others, we failed to show a correlation between changes in lung function after LVRS to improvements in RV or LV filling or function. Jorgensen and coworkers (15) used intraoperative Doppler echocardiography and pulmonary artery catheters and found that LVRS increased LV end-diastolic dimensions and filling. Patients were studied immediately postoperatively, under anesthesia, during the infusion of fluids and blood together with vasoactive medications. Mineo and associates (14) used a flowdirected, fast, thermistor-tipped volumetric pulmonary artery catheter to calculate RVEF and reported a $0.21-\mathrm{L}$ increase in cardiac index and a 3.0-ml increase in SV at rest 6 months after bilateral LVRS. During exercise, the cardiac index increased by $0.9 \mathrm{~L}, \mathrm{SV}$ by $10 \mathrm{ml}$, and RVEF by $20 \%$. An inverse relationship was found between the increase in ejection fraction and changes in the RV/TLC ( $r=-0.68, \mathrm{p}=0.01)$. Our study showed no significant change in RVEF measured by gated pooled radionuclide angiography in patients receiving LVRS compared with control subjects. Nor did it yield any correlation between changes in pulmonary function and changes in cardiac performance. Reasons for the discrepancy between their results and ours are not clear, but could be due to differences in patient selection, or surgical methods. As a result, we cannot discount a hemodynamic effect of LVRS in some patients, or effects that might be accentuated with exercise in many patients.

Certain limitations to our study are noteworthy. The sample size was small ( $4.5 \%$ of patients enrolled in NETT), one-half of the patients who had baseline RHC failed to have repeat RHC, measurements were only made at rest, we did not measure intrathoracic pressure, and MUGA and RHC were not performed on the same day. Patients who failed to have repeat RHC might have had hemodynamic effects that differed from those who underwent RHC retesting. We cannot exclude significant changes in pulmonary hemodynamics after LVRS during exercise, but not at rest, since we made no measurements during exercise. However, although small, our study was prospective, randomized, and controlled. Our patient population was extremely well characterized in terms of demographic and clinical data, radiological imaging, and pulmonary function and exercise testing. At baseline, the CV substudy patients were reflective of the NETT population at large and mirrored the NETT population with respect to the magnitude and direction of improvements in pulmonary function and exercise data after LVRS. The inability of all patients enrolled in the $\mathrm{CV}$ substudy to have repeat $\mathrm{RHC}$ emphasizes the severity of illness in this patient group, and the challenges that faced investigators and subjects in the NETT, which required exhausting and time-consuming testing. The simultaneous performance of RHC and MUGA on the same day, as well as placement of an endoesophageal catheter during RHC to simultaneously measure intrathoracic pressures, was not done for fears of overtaxing a fragile patient group, and further limiting patient recruitment and retention.

Our data show that pulmonary hypertension at rest is not a common complication of bilateral LVRS in our patient group. The lack of improvement in resting cardiac parameters postLVRS, as well as the reduction in $\mathrm{PCWP}_{\text {exp }}$, supports the notion that LVRS improves the functional status in severe emphysema predominantly via its effects on respiratory mechanics.

Conflict of Interest Statement: G.J.C. has served on advisory committees for Ortho-Biotech, Schering-Plough, Boehringer Ingelheim, Actelion, Shire, and Sepracor Pharmaceuticals; all of these sums were less than $\$ 2,500$; he has also received research grants from Schering-Plough, Boehringer Ingelheim, Actelion, GlaxoSmithKline, Advanta, Daiichi Asubio, Pfizer, Roche and Sepracor Pharmaceuticals, Emphasys Medical, Inc., and Aeris Therapeutics. S.M.S. has no financial relationship with a commercial entity that has an interest in the subject of this manuscript. J.A.F. has no financial relationship with a commercial entity that has an interest in the subject of this manuscript. J.P.G. has no financial relationship with a commercial entity that has an interest in the subject of this manuscript. A.L.S. has no financial relationship with a commercial entity that has an interest in the subject of this manuscript. N.B.P. has no financial relationship with a commercial entity that has an interest in the subject of this manuscript. H.E.F. has no financial relationship with a commercial entity that has an interest in the subject of this manuscript. O.A.M. has no financial relationship with a commercial entity that has an interest in the subject of this manuscript. A.P.F. has no financial relationship with a commercial entity that has an interest in the subject of this manuscript.

The members of the National Emphysema Treatment Trial Research Group were as follows: Office of the Chair of the Steering Committee, University of Pennsylvania, Philadelphia, PA: Alfred P. Fishman, M.D. (Chair); Betsy Ann Bozzarello; Ameena Al-Amin. Clinical Centers: Baylor College of Medicine, Houston, TX: Marcia Katz, M.D. (Principal Investigator); Carolyn Wheeler, R.N., B.S.N. (Principal Clinic Coordinator); Elaine Baker, R.R.T., R.P.F.T.; Peter Barnard, Ph.D., R.P.F.T.; Phil Cagle, M.D.; James Carter, M.D.; Sophia Chatziioannou, M.D.; Karla Conejo-Gonzales; Kimberly Dubose, R.R.T.; John Haddad, M.D.; David Hicks, R.R.T., R.P.F.T.; Neal Kleiman, M.D.; Mary Milburn-Barnes, C.R.T.T.; Chinh Nguyen, R.P.F.T.; Michael Reardon, M.D.; Joseph Reeves-Viets, M.D.; Steven Sax, M.D.; Amir Sharafkhaneh, M.D.; Owen Wilson, Ph.D.; Christine Young, P.T.; Rafael Espada, M.D. (Principal Investigator 1996-2002); Rose Butanda (1999-2001); Minnie Ellisor (2002); Pamela Fox, M.D. (1999-2001); Katherine Hale, M.D. (1998-2000); Everett Hood, 
R.P.F.T. (1998-2000); Amy Jahn (1998-2000); Satish Jhingran, M.D. (19982001); Karen King, R.P.F.T. (1998-1999); Charles Miller III, Ph.D. (1996-1999); Imran Nizami, M.D. (Co-Principal Investigator, 2000-2001); Todd Officer (19982000); Jeannie Ricketts (1998-2000); Joe Rodarte, M.D. (Co-Principal Investigator 1996-2000); Robert Teague, M.D. (Co-Principal Investigator 1999-2000); Kedren Williams (1998-1999). Brigham and Women's Hospital, Boston, MA: John Reilly, M.D. (Principal Investigator); David Sugarbaker, M.D. (Co-Principal Investigator); Carol Fanning, R.R.T. (Principal Clinic Coordinator); Simon Body, M.D.; Sabine Duffy, M.D.; Vladmir Formanek, M.D.; Anne Fuhlbrigge, M.D.; Philip Hartigan, M.D.; Sarah Hooper, E.P.; Andetta Hunsaker, M.D.; Francine Jacobson, M.D.; Marilyn Moy, M.D.; Susan Peterson, R.R.T.; Roger Russell, M.D.; Diane Saunders; Scott Swanson, M.D. (Co-Principal Investigator, 1996-2001). Cedars-Sinai Medical Center, Los Angeles, CA: Rob McKenna, M.D. (Principal Investigator); Zab Mohsenifar, M.D. (Co-Principal Investigator); Carol Geaga, R.N. (Principal Clinic Coordinator); Manmohan Biring, M.D.; Susan Clark, R.N., M.N.; Jennifer Cutler, M.D.; Robert Frantz, M.D.; Peter Julien, M.D.; Michael Lewis, M.D.; Jennifer Minkoff-Rau, M.S.W.; Valentina Yegyan, B.S., C.P.F.T.; Milton Joyner, B.A. (1996-2002). Cleveland Clinic Foundation, Cleveland, $\mathrm{OH}$ : Malcolm DeCamp, M.D. (Principal Investigator); James Stoller, MD (Co-Principal Investigator); Yvonne Meli, R.N., (Principal Clinic Coordinator); John Apostolakis, M.D.; Darryl Atwell, M.D.; Jeffrey Chapman, M.D.; Pierre DeVilliers, M.D.; Raed Dweik, M.D.; Erik Kraenzler, M.D.; Rosemary Lann, L.I.S.W.; Nancy Kurokawa, R.R.T., C.P.F.T.; Scott Marlow, R.R.T.; Kevin McCarthy, R.C.P.T.; Pricilla McCreight, R.R.T., C.P.F.T.; Atul Mehta, M.D.; Moulay Meziane, M.D.; Omar Minai, M.D.; Mindi Steiger, R.R.T.; Kenneth White, R.P.F.T.; Janet Maurer, M.D. (Principal Investigator, 1996-2001); Terri Durr, RN (20002001); Charles Hearn, D.O. (1998-2001); Susan Lubell, P.A.-C. (1999--2000); Peter O'Donovan, M.D. (1998-2003); Robert Schilz, D.O. (1998-2002). Columbia University, New York, NY in consortium with Long Island Jewish Medical Center, New Hyde Park, NY: Mark Ginsburg, M.D. (Principal Investigator); Byron Thomashow, M.D. (Co-Principal Investigator); Patricia Jellen, M.S.N., R.N. (Principal Clinic Coordinator); John Austin, M.D.; Matthew Bartels, M.D.; Yahya Berkmen, M.D.; Patricia Berkoski, M.S., R.R.T. (Site coordinator, L.I.J.); Frances Brogan, M.S.N., R.N.; Amy Chong, B.S., C.R.T.; Glenda DeMercado, B.S.N.; Angela DiMango, M.D.; Sandy Do, M.S., P.T.; Bessie Kachulis, M.D.; Arfa Khan, M.D.; Berend Mets, M.D.; Mitchell O'Shea, B.S., R.T., C.P.F.T.; Gregory Pearson, M.D.; Leonard Rossoff, M.D.; Steven Scharf, M.D., Ph.D. (Co-Principal Investigator, 1998-2002); Maria Shiau, M.D.; Paul Simonelli, M.D.; Kim Stavrolakes, M.S., P.T.; Donna Tsang, B.S.; Denise Vilotijevic, M.S., P.T.; Chun Yip, M.D.; Mike Mantinaos, M.D. (1998-2001); Kerri McKeon, B.S., R.R.T., R.N. (1998-1999); Jacqueline Pfeffer, M.P.H., P.T. (19972002). Duke University Medical Center, Durham, NC: Neil Maclntyre, M.D. (Principal Investigator); R. Duane Davis, M.D. (Co-Principal Investigator); John Howe, R.N. (Principal Clinic Coordinator); R. Edward Coleman, M.D.; Rebecca Crouch, R.P.T.; Dora Greene; Katherine Grichnik, M.D.; David Harpole, Jr., M.D.; Abby Krichman, R.R.T.; Brian Lawlor, R.R.T.; Holman McAdams, M.D.; John Plankeel, M.D.; Susan Rinaldo-Gallo, M.E.D.; Sheila Shearer, R.R.T.; Jeanne Smith, A.C.S.W.; Mark Stafford-Smith, M.D.; Victor Tapson, M.D.; Mark Steele, M.D. (1998-1999); Jennifer Norten, MD (1998-1999). Mayo Foundation, Rochester, MN: James Utz, M.D. (Principal Investigator); Claude Deschamps, M.D. (Co-Principal Investigator); Kathy Mieras, C.C.R.P. (Principal Clinic Coordinator); Martin Abel, M.D.; Mark Allen, M.D.; Deb Andrist, R.N.; Gregory Aughenbaugh, M.D.; Sharon Bendel, R.N.; Eric Edell, M.D.; Marlene Edgar; Bonnie Edwards; Beth Elliot, M.D.; James Garrett, R.R.T.; Delmar Gillespie, M.D.; Judd Gurney, M.D.; Boleyn Hammel; Karen Hanson, R.R.T.; Lori Hanson, R.R.T.; Gordon Harms, M.D.; June Hart; Thomas Hartman, M.D.; Robert Hyatt, M.D.; Eric Jensen, M.D.; Nicole Jenson, R.R.T.; Sanjay Kalra, M.D.; Philip Karsell, M.D.; Jennifer Lamb; David Midthun, M.D.; Carl Mottram, R.R.T.; Stephen Swensen, M.D.; Anne-Marie Sykes, M.D.; Karen Taylor; Norman Torres, M.D.; Rolf Hubmayr, M.D. (1998-2000); Daniel Miller, M.D. (1999-2002); Sara Bartling, R.N. (1998-2000); Kris Bradt (1998-2002). National Jewish Medical and Research Center, Denver, CO: Barry Make, M.D. (Principal Investigator); Marvin Pomerantz, M.D. (Co-Principal Investigator); Mary Gilmartin, R.N., R.R.T. (Principal Clinic Coordinator); Joyce Canterbury; Martin Carlos; Phyllis Dibbern, P.T.; Enrique Fernandez, M.D.; Lisa Geyman, M.S.P.T.; Connie Hudson; David Lynch, M.D.; John Newell, M.D.; Robert Quaife, M.D.; Jennifer Propst, R.N.; Cynthia Raymond, M.S.; Jane Whalen-Price, P.T.; Kathy Winner, O.T.R.; Martin Zamora, M.D.; Reuben Cherniack, M.D. (Principal Investigator, 1997-2000). Ohio State University, Columbus, OH: Philip Diaz, M.D. (Principal Investigator); Patrick Ross, M.D. (Co-Principal Investigator); Tina Bees (Principal Clinic Coordinator); Jan Drake; Charles Emery, Ph.D.; Mark Gerhardt, M.D., Ph.D.; Mark King, M.D.; David Rittinger; Mahasti Rittinger. Saint Louis University, Saint Louis, MO: Keith Naunheim, M.D. (Principal Investigator); Robert Gerber, M.D. (Co-Principal Investigator); Joan Osterloh, R.N., M.S.N. (Principal Clinic Coordinator); Susan Borosh; Willard Chamberlain, D.O.; Sally Frese; Alan Hibbit; Mary Ellen Kleinhenz, M.D.; Gregg Ruppel; Cary Stolar, M.D.; Janice Willey; Francisco Alvarez, M.D. (CoPrincipal Investigator, 1999-2002); Cesar Keller, M.D. (Co-Principal Investigator, 1996-2000). Temple University, Philadelphia, PA: Gerard Criner, M.D. (Principal Investigator); Satoshi Furukawa, M.D. (Co-Principal Investigator); Anne Marie Kuzma, R.N., M.S.N. (Principal Clinic Coordinator); Roger Barnette, M.D.; Neil Brister, M.D.; Kevin Carney, R.N., C.C.T.C.; Wissam Chatila, M.D.; Francis Cordova, M.D.; Gilbert D’Alonzo, D.O.; Michael Keresztury, M.D.; Karen Kirsch; Chul Kwak, M.D.; Kathy Lautensack, R.N., B.S.N.; Madelina Lorenzon, C.P.F.T.; Ubaldo Martin, M.D.; Peter Rising, M.S.; Scott Schartel, M.D.; John Travaline, M.D.; Gwendolyn Vance, R.N., C.C.T.C.; Phillip Boiselle, M.D. (1997-2000); Gerald O'Brien, M.D. (1997-2000). University of California, San Diego, San Diego, CA: Andrew Ries, M.D., M.P.H. (Principal Investigator); Robert Kaplan, Ph.D. (CoPrincipal Investigator); Catherine Ramirez, B.S., R.C.P. (Principal Clinic Coordinator); David Frankville, M.D.; Paul Friedman, M.D.; James Harrell, M.D.; Jeffery
Johnson; David Kapelanski, M.D.; David Kupferberg, M.D., M.P.H.; Catherine Larsen, M.P.H.; Trina Limberg, R.R.T.; Michael Magliocca, R.N., C.N.P.; Frank J. Papatheofanis, M.D., Ph.D.; Dawn Sassi-Dambron, R.N.; Melissa Weeks. University of Maryland at Baltimore, Baltimore, MD in consortium with Johns Hopkins Hospital, Baltimore, MD: Mark Krasna, M.D. (Principal Investigator); Henry Fessler, M.D. (Co-Principal Investigator); Iris Moskowitz (Principal Clinic Coordinator); Timothy Gilbert, M.D.; Jonathan Orens, M.D.; Steven Scharf, M.D., Ph.D.; David Shade; Stanley Siegelman, M.D.; Kenneth Silver, M.D.; Clarence Weir; Charles White, M.D. University of Michigan, Ann Arbor, MI: Fernando Martinez, M.D. (Principal Investigator); Mark lannettoni, M.D. (Co-Principal Investigator); Catherine Meldrum, B.S.N., R.N., C.C.R.N. (Principal Clinic Coordinator); William Bria, M.D.; Kelly Campbell; Paul Christensen, M.D.; Kevin Flaherty, M.D.; Steven Gay, M.D.; Paramjit Gill, R.N.; Paul Kazanjian, M.D.; Ella Kazerooni, M.D.; Vivian Knieper; Tammy Ojo, M.D.; Lewis Poole; Leslie Quint, M.D.; Paul Rysso; Thomas Sisson, M.D.; Mercedes True; Brian Woodcock, M.D.; Lori Zaremba, R.N. University of Pennsylvania, Philadelphia, PA: Larry Kaiser, M.D. (Principal Investigator); John Hansen-Flaschen, M.D. (Co-Principal Investigator); Mary Louise Dempsey, B.S.N., R.N. (Principal Clinic Coordinator); Abass Alavi, M.D.; Theresa Alcorn, Selim Arcasoy, M.D.; Judith Aronchick, M.D.; Stanley Aukberg, M.D.; Bryan Benedict, RRT; Susan Craemer, BS, RRT, C.P.F.T.; Ron Daniele, M.D.; Jeffrey Edelman, M.D.; Warren Gefter, M.D.; Laura Kotler-Klein, M.S.S.; Robert Kotloff, M.D.; David Lipson, M.D.; Wallace Miller, Ir., M.D.; Richard O'Connell, R.P.F.T.; Staci Opelman, M.S.W.; Harold Palevsky, M.D.; William Russell, R.P.F.T.; Heather Sheaffer, M.S.W.; Rodney Simcox, B.S.R.T., R.R.T.; Susanne Snedeker, RRT, C.P.F.T.; Jennifer Stone-Wynne, M.S.W.; Gregory Tino, M.D.; Peter Wahl; James Walter, RPFT; Patricia Ward; David Zisman, M.D.; James Mendez, M.S.N., C.R.N.P. (1997-2001); Angela Wurster, MSN, CRNP (1997-1999). University of Pittsburgh, Pittsburgh, PA: Frank Sciurba, M.D. (Principal Investigator); James Luketich, M.D. (Co-Principal Investigator); Colleen Witt, M.S. (Principal Clinic Coordinator); Gerald Ayres; Michael Donahoe, M.D.; Carl Fuhrman, M.D.; Robert Hoffman, M.D.; Joan Lacomis, M.D.; Joan Sexton; William Slivka; Diane Strollo, M.D.; Erin Sullivan, M.D. Tomeka Simon; Catherine Wrona, R.N., B.S.N.; Gerene Bauldoff, R.N., M.S.N. (1997-2000); Manuel Brown, M.D. (1997-2002); Elisabeth George, R.N., M.S.N. (Principal Clinic Coordinator 1997-2001); Robert Keenan, M.D. (Co-Principal Investigator 1997-2000); Theodore Kopp, M.S. (1997-1999); Laurie Silfies (19972001). University of Washington, Seattle, WA: Joshua Benditt, M.D. (Principal Investigator), Douglas Wood, M.D. (Co-Principal Investigator); Margaret Snyder, M.N. (Principal Clinic Coordinator); Kymberley Anable; Nancy Battaglia; Louie Boitano; Andrew Bowdle, M.D.; Leighton Chan, M.D.; Cindy Chwalik; Bruce Culver, M.D.; Thurman Gillespy, M.D.; David Godwin, M.D.; Jeanne Hoffman; Andra Ibrahim, M.D.; Diane Lockhart; Stephen Marglin, M.D.; Kenneth Martay, M.D.; Patricia McDowell; Donald Oxorn, M.D.; Liz Roessler; Michelle Toshima; Susan Golden (1998-2000). Other Participants: Agency for Healthcare Research and Quality, Rockville, MD: Lynn Bosco, M.D., M.P.H.; Yen-Pin Chiang, Ph.D.; Carolyn Clancy, M.D.; Harry Handelsman, D.O. Centers for Medicare and Medicaid Services, Baltimore, MD: Steven M. Berkowitz, Ph.D.; Tanisha Carino, Ph.D.; Joe Chin, M.D.; JoAnna Baldwin; Karen McVearry; Anthony Norris; Sarah Shirey; Claudette Sikora; Steven Sheingold, Ph.D. (1997-2004). Coordinating Center, The Johns Hopkins University, Baltimore, MD: Steven Piantadosi, M.D., Ph.D. (Principal Investigator); James Tonascia, Ph.D (Co-Principal Investigator); Patricia Belt; Amanda Blackford, Sc.M.; Karen Collins; Betty Collison; Ryan Colvin, M.P.H.; John Dodge; Michele Donithan, M.H.S.; Vera Edmonds; Gregory L. Foster, M.A.; Julie Fuller; Judith Harle; Rosetta Jackson; Shing Lee, Sc.M.; Charlene Levine; Hope Livingston; Jill Meinert; Jennifer Meyers; Deborah Nowakowski; Kapreena Owens; Shangqian Qi, M.D.; Michael Smith; Brett Simon, M.D.; Paul Smith; Alice Sternberg, ScM; Mark Van Natta, M.H.S.; Laura Wilson, Sc.M.; Robert Wise, M.D. Cost Effectiveness Subcommittee: Robert M. Kaplan, Ph.D. (Chair); J. Sanford Schwartz, M.D. (CoChair); Yen-Pin Chiang, Ph.D.; Marianne C. Fahs, Ph.D.; A. Mark Fendrick, M.D.; Alan J. Moskowitz, M.D.; Dev Pathak, Ph.D.; Scott Ramsey, M.D., Ph.D.; Steven Sheingold, Ph.D.; A. Laurie Shroyer, Ph.D.; Judith Wagner, Ph.D.; Roger Yusen, M.D. Cost Effectiveness Data Center, Fred Hutchinson Cancer Research Center, Seattle, WA: Scott Ramsey, M.D., Ph.D. (Principal Investigator); Ruth Etzioni, Ph.D.; Sean Sullivan, Ph.D.; Douglas Wood, M.D.; Thomas Schroeder, M.A.; Karma Kreizenbeck; Kristin Berry, M.S.; Nadia Howlader, M.S. CT Scan Image Storage and Analysis Center, University of lowa, lowa City, IA: Eric Hoffman, Ph.D. (Principal Investigator); Janice Cook-Granroth, B.S.; Angela Delsing, R.T.; Junfeng Guo, Ph.D.; Geoffrey McLennan, M.D.; Brian Mullan, M.D.; Chris Piker, B.S.; Joseph Reinhardt, Ph.D.; Blake Robinswood; Jered Sieren, R.T.R.; William Stanford, M.D. Data and Safety Monitoring Board: John A. Waldhausen, M.D. (Chair); Gordon Bernard, M.D.; David DeMets, Ph.D.; Mark Ferguson, M.D.; Eddie Hoover, M.D.; Robert Levine, M.D.; Donald Mahler, M.D.; A. John McSweeny, Ph.D.; Jeanine Wiener-Kronish, M.D.; O. Dale Williams, Ph.D.; Magdy Younes, M.D. Marketing Center, Temple University, Philadelphia, PA: Gerard Criner, M.D. (Principal Investigator); Charles Soltoff, M.B.A. Project Office, National Heart, Lung, and Blood Institute, Bethesda, MD: Gail Weinmann, M.D. (Project Officer); Joanne Deshler (Contracting Officer); Dean Follmann, Ph.D.; James Kiley, Ph.D.; Margaret Wu, Ph.D. (19962001). Other acknowledgments: Arthur Gelb, M.D., Lakewood Regional Medical Center, Lakewood, CA.

\section{References}

1. Scharf SM. Cardiovascular effects of emphysema. In: Argenziano M, Ginsburg ME. Lung volume reduction surgery. Totowa, NJ: Humana Press; 2001. 
2. Stark RD, Finnegan P, Bishop JM. Daily requirement of oxygen to reverse pulmonary hypertension in patients with chronic bronchitis. BMJ 1972;3:724-728.

3. Stark RD, Finnegan P, Bishop JM. Long-term domiciliary oxygen in chronic bronchitis with pulmonary hypertension. BMJ 1973;3:467-470.

4. Timms RM, Khaja FU, Williams GW. Hemodynamic response to oxygen therapy in chronic obstructive pulmonary disease. Ann Intern Med 1985;102:29-36.

5. Weitzenblum E, Sautegeau A, Ehrhart M, Mammosser M, Pelletier A. Long-term oxygen therapy can reverse the progression of pulmonary hypertension in patients with chronic obstructive pulmonary disease. Am Rev Respir Dis 1985;131:493-498.

6. Nakhjavan FK, Palmer WH, McGregor M. Influence of respiration on venous return in pulmonary emphysema. Circulation 1966;33:8-16.

7. Fessler HE, Brower RG, Shapiro EP, Permutt S. Effects of positive endexpiratory pressure and body position on pressure in the thoracic great veins. Am Rev Respir Dis 1993;148:1657-1664.

8. Robotham JL, Scharf SM. Effects of positive and negative pressure ventilation on cardiac performance. Clin Chest Med 1983;4:161-187.

9. Fessler HE, Brower RG, Wise RA, Permutt S. Effects of positive endexpiratory pressure on the canine venous return curve. Am Rev Respir Dis 1992;146:4-10.

10. Scharf S. Right ventricular load tolerance: role of left ventricular function. In: Perspectives en Reanimation, Les Interactions Cardio-Pulmonaires Societe de Re'animation de Langue Francais. 1994. pp. 17-28.

11. Sciurba FC, Rogers RM, Keenan RJ, Slivka WA, Gorcsan J III, Ferson PF, Holbert JM, Brown ML, Landreneau RJ. Improvement in pulmonary function and elastic recoil after lung-reduction surgery for diffuse emphysema. N Engl J Med 1996;334:1095-1099.

12. Kubo K, Koizumi T, Fujimoto K, Matsuzawa Y, Yamanda T, Haniuda M, Takahashi S. Effects of lung volume reduction surgery on exercise pulmonary hemodynamics in severe emphysema. Chest 1998;114:15751582.

13. Oswald-Mammosser M, Kessler R, Massard G, Wihlm JM, Weitzenblum E, Lonsdorfer J. Effect of lung volume reduction surgery on gas exchange and pulmonary hemodynamics at rest and during exercise. Am J Respir Crit Care Med 1998;158:1020-1025.

14. Mineo TC, Pompeo E, Rogliani P, Dauri M, Turani F, Bollero P, Magliocchetti N. Effect of lung volume reduction surgery for severe emphysema on right ventricular function. Am J Respir Crit Care Med 2002;165:489-494.

15. Jorgensen K, Houltz E, Westfelt U, Nilsson F, Schersten H, Ricksten SE. Effects of lung volume reduction surgery on left ventricular diastolic filling and dimensions in patients with severe emphysema. Chest 2003; $124: 1863-1870$.

16. Weg IL, Rossoff L, McKeon K, Michael Graver L, Scharf SM. Development of pulmonary hypertension after lung volume reduction surgery. Am J Respir Crit Care Med 1999;159:552-556.

17. Haniuda M, Kubo K, Fujimoto K, Aoki T, Yamanda T, Amano J. Different effects of lung volume reduction surgery and lobectomy on pulmonary circulation. Ann Surg 2000;231:119-125.

18. Haniuda M, Kubo K, Fujimoto K, Honda T, Yamaguchi S, Yoshida $\mathrm{K}$, Amano J. Effects of pulmonary artery remodeling on pulmonary circulation after lung volume reduction surgery. Thorac Cardiovasc Surg 2003;51:154-158.
19. National Emphysema Treatment Trial Research Group. Rationale and design of the National Emphysema Treatment Trial: a prospective randomized trial of lung volume reduction surgery. Chest 1999;116:1750.

20. American Thoracic Society. Standardization of spirometry: 1994 update. Am J Respir Crit Care Med 1995;152:1107.

21. American Thoracic Society. Lung function testing selection of reference values and interpretative strategies. Am Rev Respir Dis 1991;144:12021218.

22. American Thoracic Society. Single-breath carbon monoxide diffusing capacity (transfer factor): recommendations for a standard technique1995 update. Am J Respir Crit Care Med 1995;152:2185-2198.

23. Crapo RO, Morris AH, Gardner RM. Reference spirometric values using techniques and equipment that meet ATS recommendations. Am Rev Respir Dis 1981;123:659-664.

24. National Emphysema Treatment Trial Research Group. A randomized trial comparing lung volume reduction surgery with medical therapy for severe emphysema. N Engl J Med 2003;348:2059-2073.

25. Dantzker DR, Scharf SM. Surgery to reduce lung volume. $N$ Engl J Med 1996;334:1128-1129.

26. Kessler R, Faller M, Fourgaut G, Mennecier B, Weitzenblum E. Predictive factors of hospitalization for acute exacerbation in a series of 64 patients with chronic obstructive pulmonary disease. Am J Respir Crit Care Med 1999;159:158-164.

27. Olvey SK, Reduto LA, Stevens PM, Deaton WJ, Miller RR. First pass radionuclide assessment of right and left ventricular ejection fraction in chronic pulmonary disease: effect of oxygen upon exercise response. Chest 1980;78:4-9.

28. Jones NL, Burrows B, Fletcher CM. Serial studies of 100 patients with chronic airway obstruction in London and Chicago. Thorax 1967;22: 327-335.

29. Boushy SF, Thompson HK Jr, North LB, Beale AR, Snow TR. Prognosis in chronic obstructive pulmonary disease. Am Rev Respir Dis 1973; 108:1373-1383.

30. Powell LL, Ha HP, Serna DL, Brenner M, Gaon M, Jalal R, Stemmer $\mathrm{E}$, Chen JC. Pulmonary vascular pressures increase after lung volume reduction surgery in rabbits with more severe emphysema. J Surg Res 2000;92:157-164.

31. Chen JC, Powell LL, Serna DL, Gaon M, Jalal R, Huh J, McKenna R, Gelb A, Wang N, Stemmer E, et al. Pulmonary artery pressure: an intraoperative guide to limiting resection volume. J Surg Res 1999; 82:137-145.

32. Scharf SM, Iqbal M, Keller C, Criner G, Lee S, Fessler HE; National Emphysema Treatment Trial (NETT) Group. Hemodynamic characterization of patients with severe emphysema. Am J Respir Crit Care Med 2002;166:314-322.

33. Lockhart A, Tzareva M, Nader F, Leblanc P, Schrijen F, Sadoul P. Elevated pulmonary artery wedge pressure at rest and during exercise in chronic bronchitis: fact or fancy. Clin Sci 1969;37:503-517.

34. Burrows B, Kettel LJ, Niden AH, Rabinowitz M, Diener CF. Patterns of cardiovascular dysfunction in chronic obstructive lung disease. N Engl J Med 1972;286:912-918.

35. Butler J, Schrijen F, Henriquez A, Polu JM, Albert RK. Cause of the raised wedge pressure on exercise in chronic obstructive pulmonary disease. Am Rev Respir Dis 1988;138:350-354. 